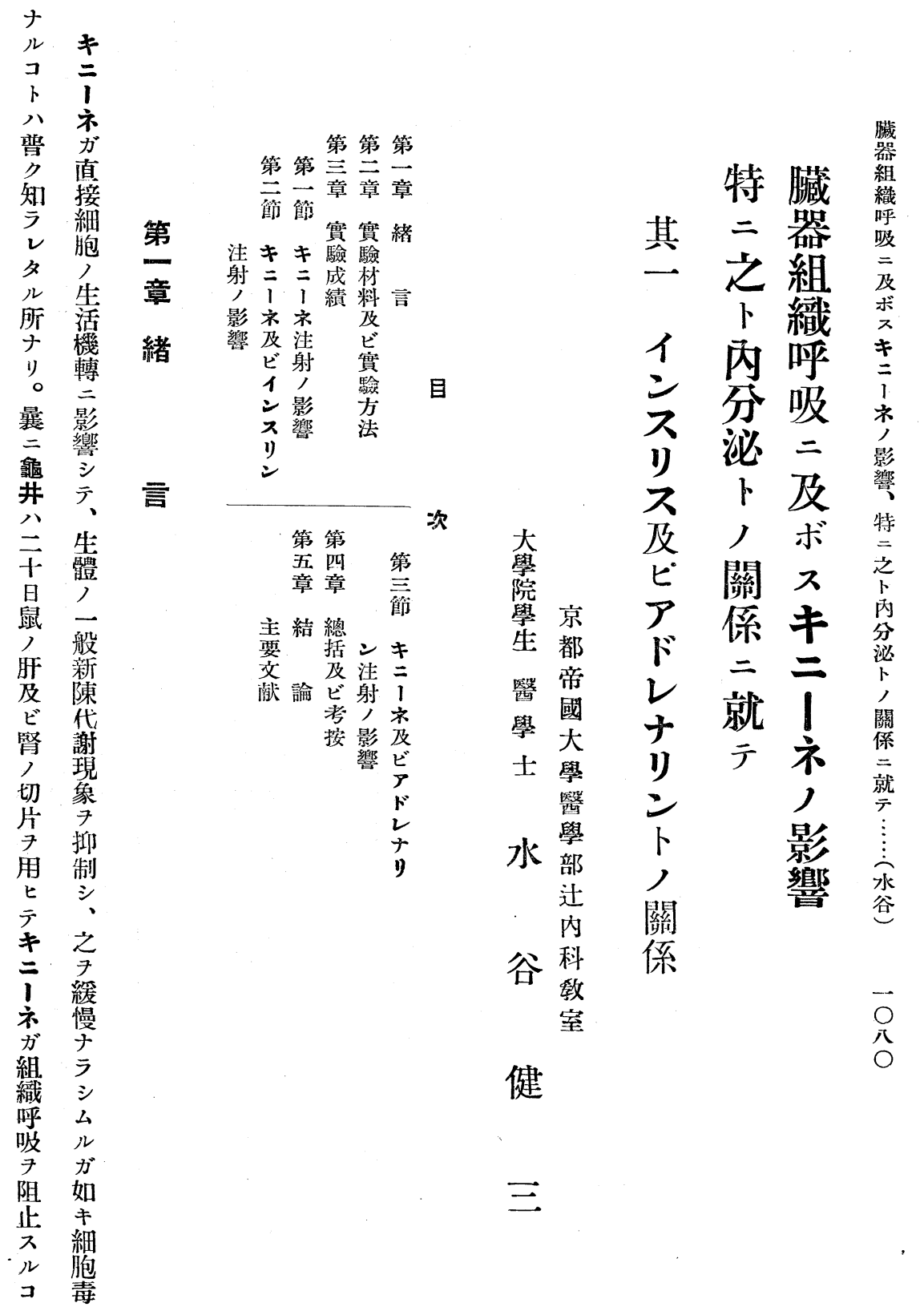



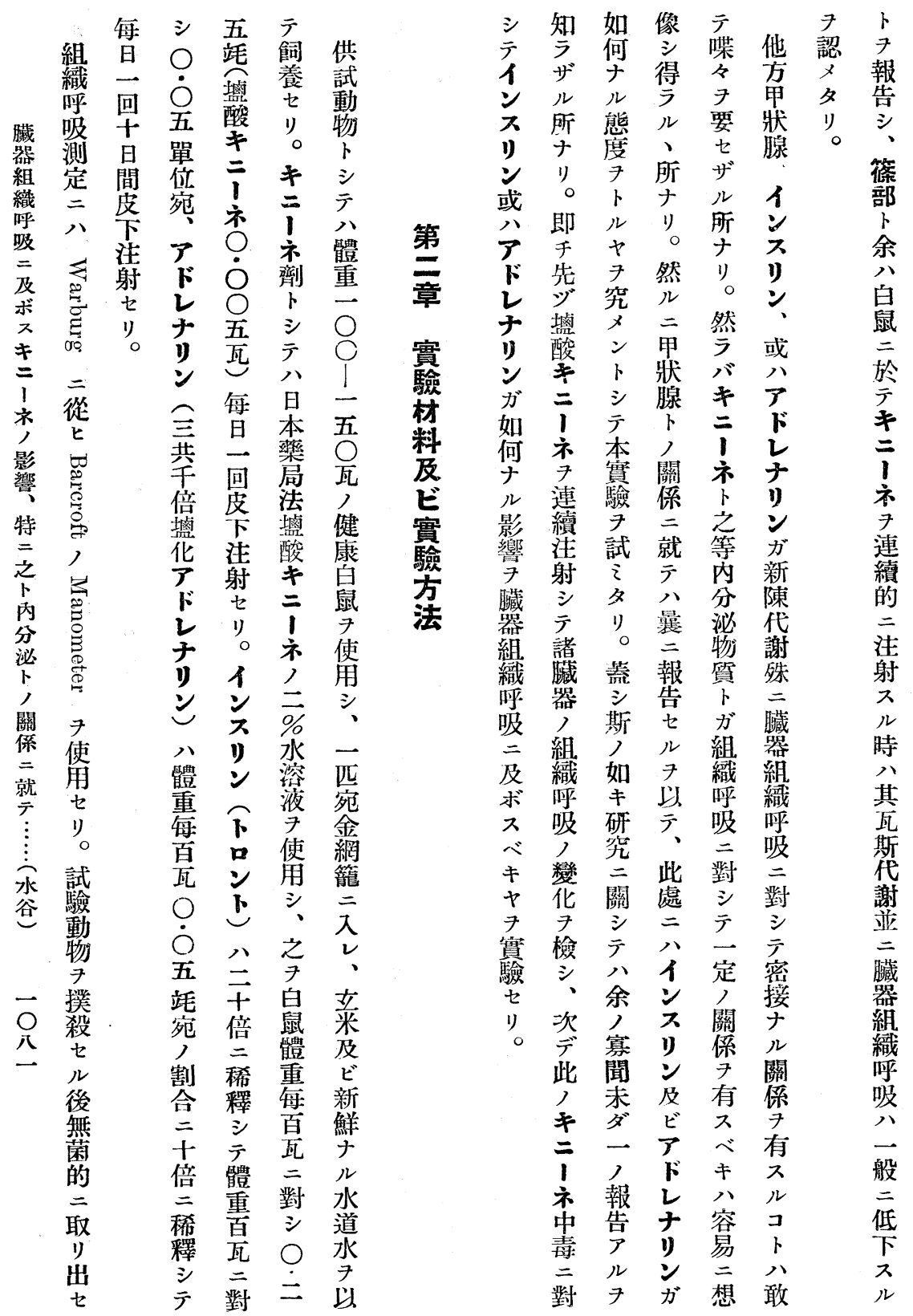


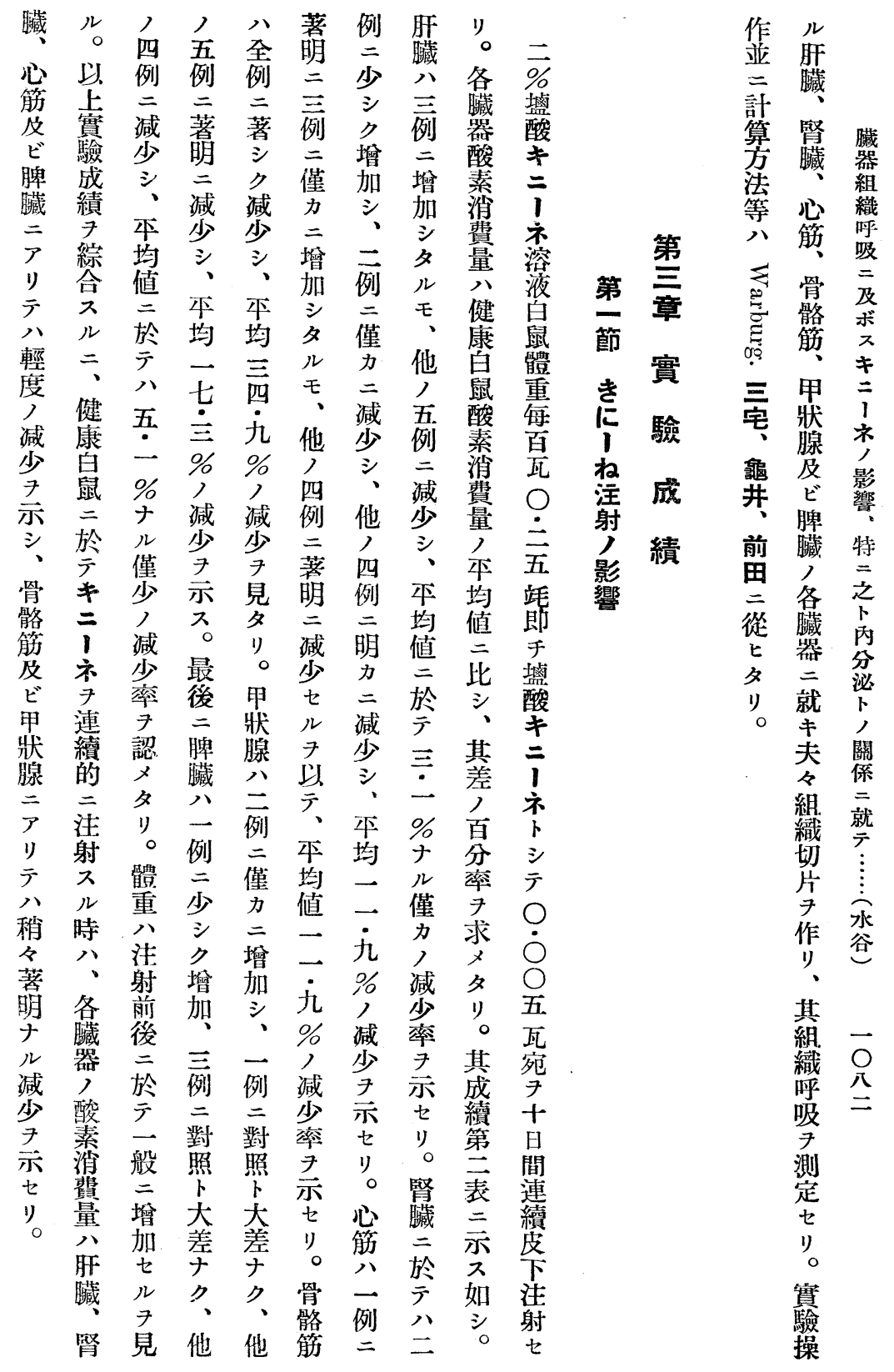




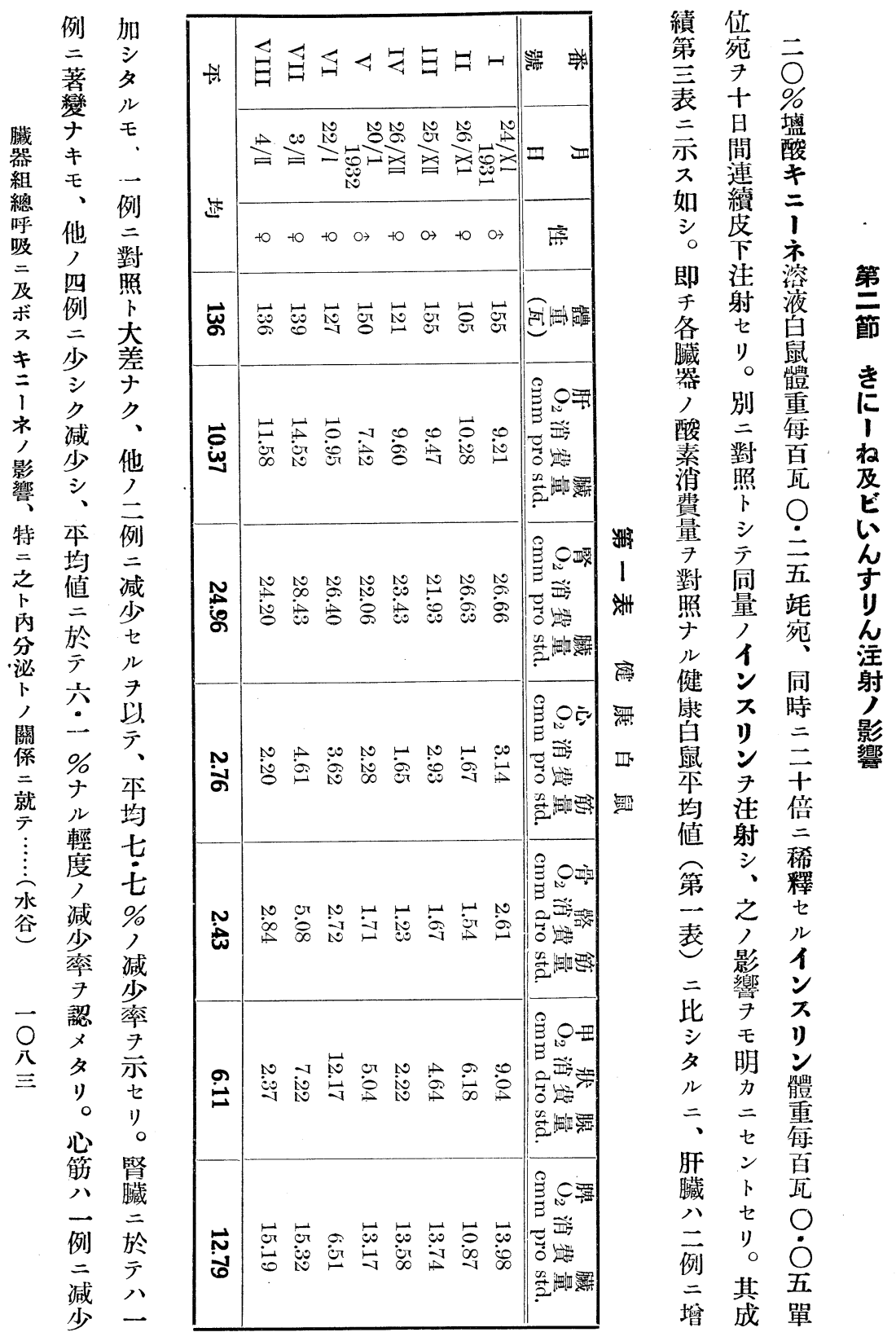




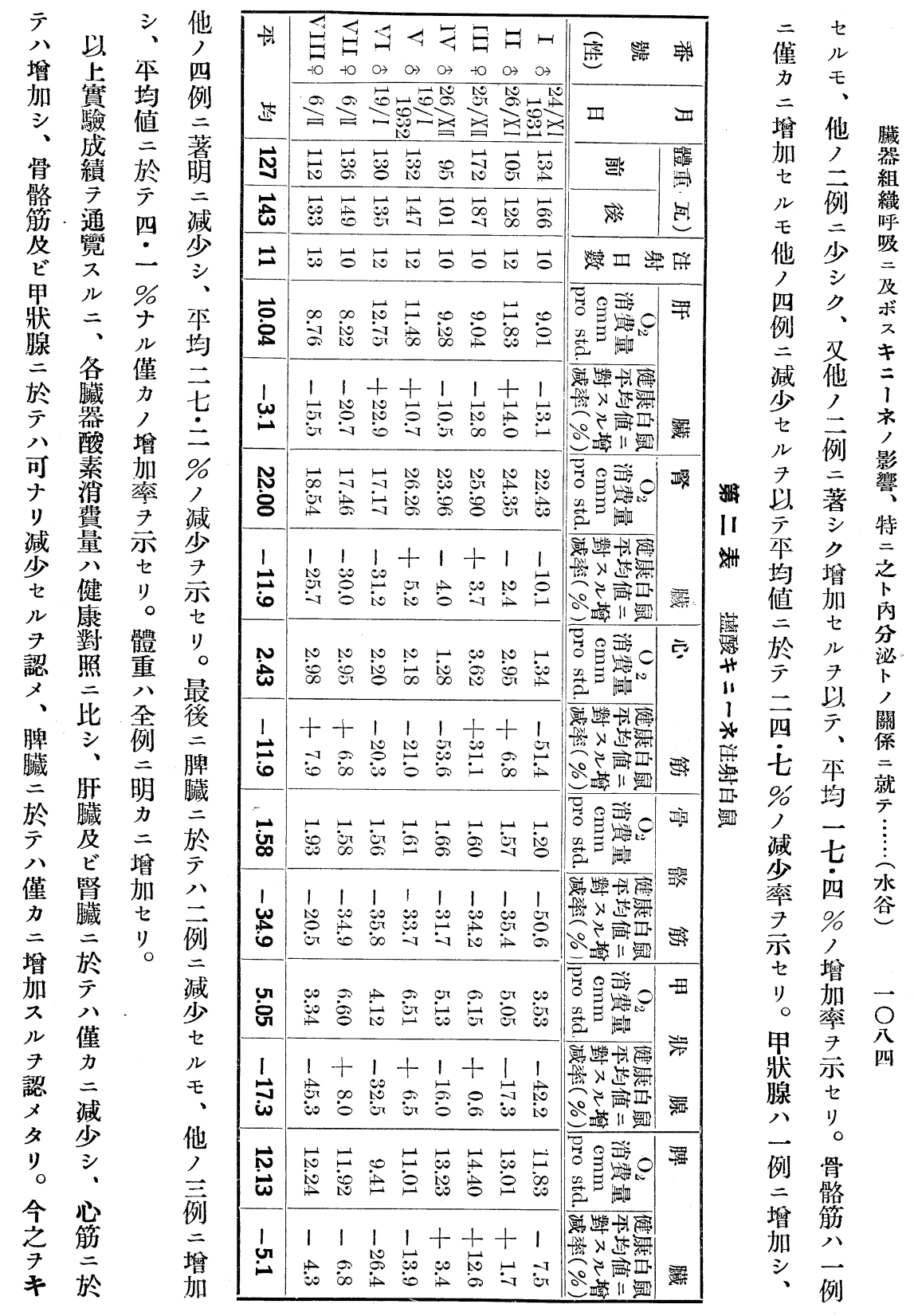




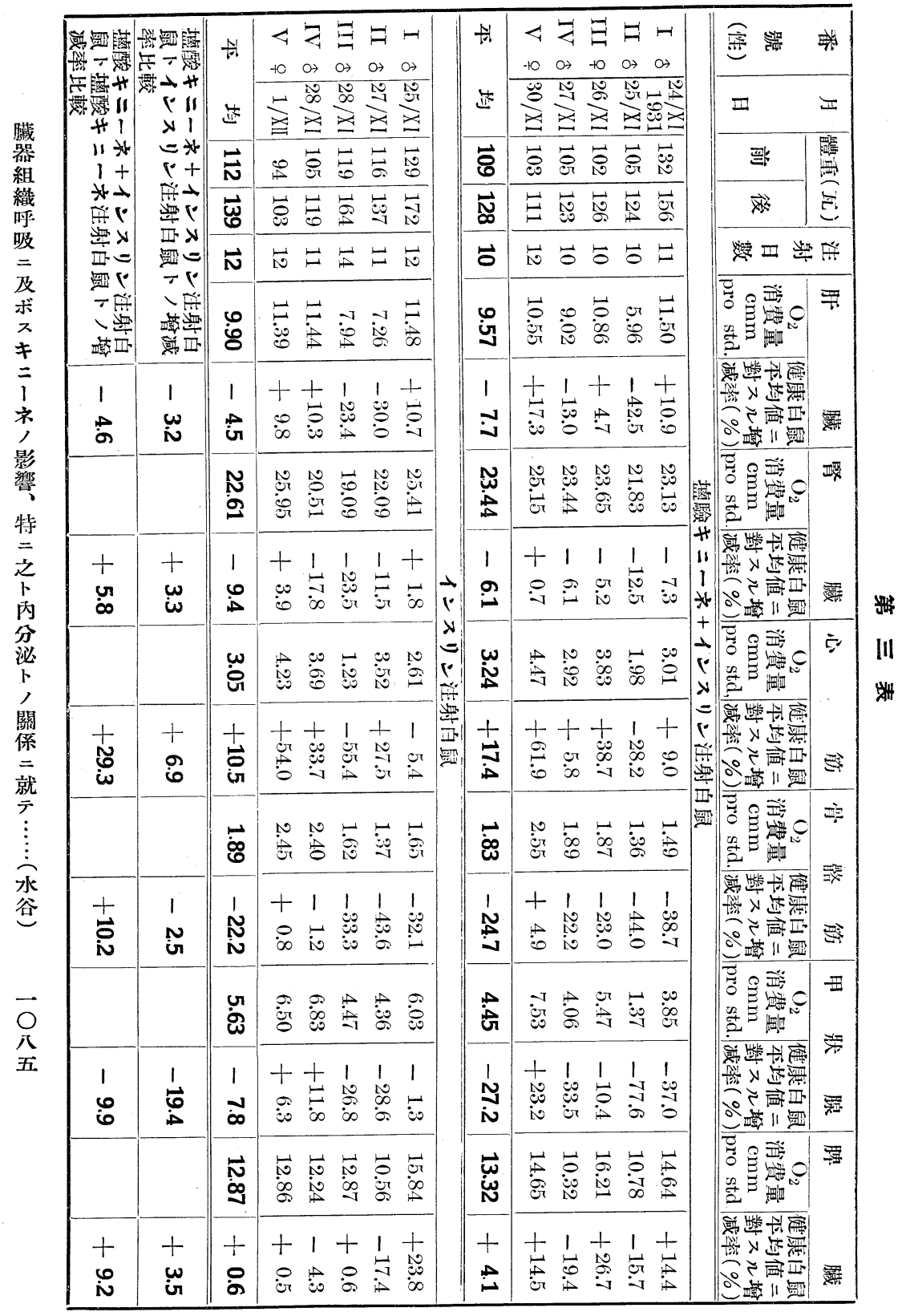



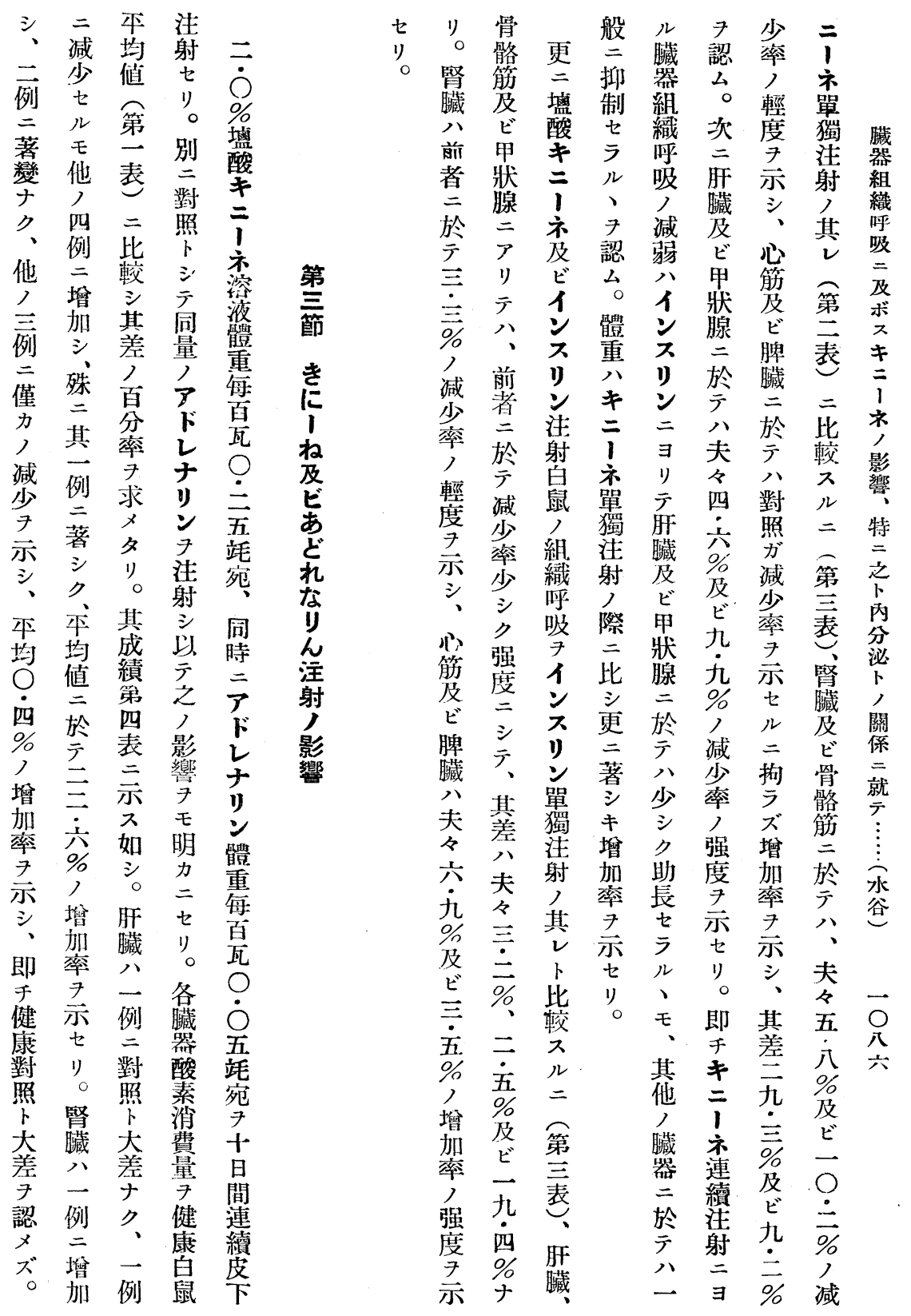


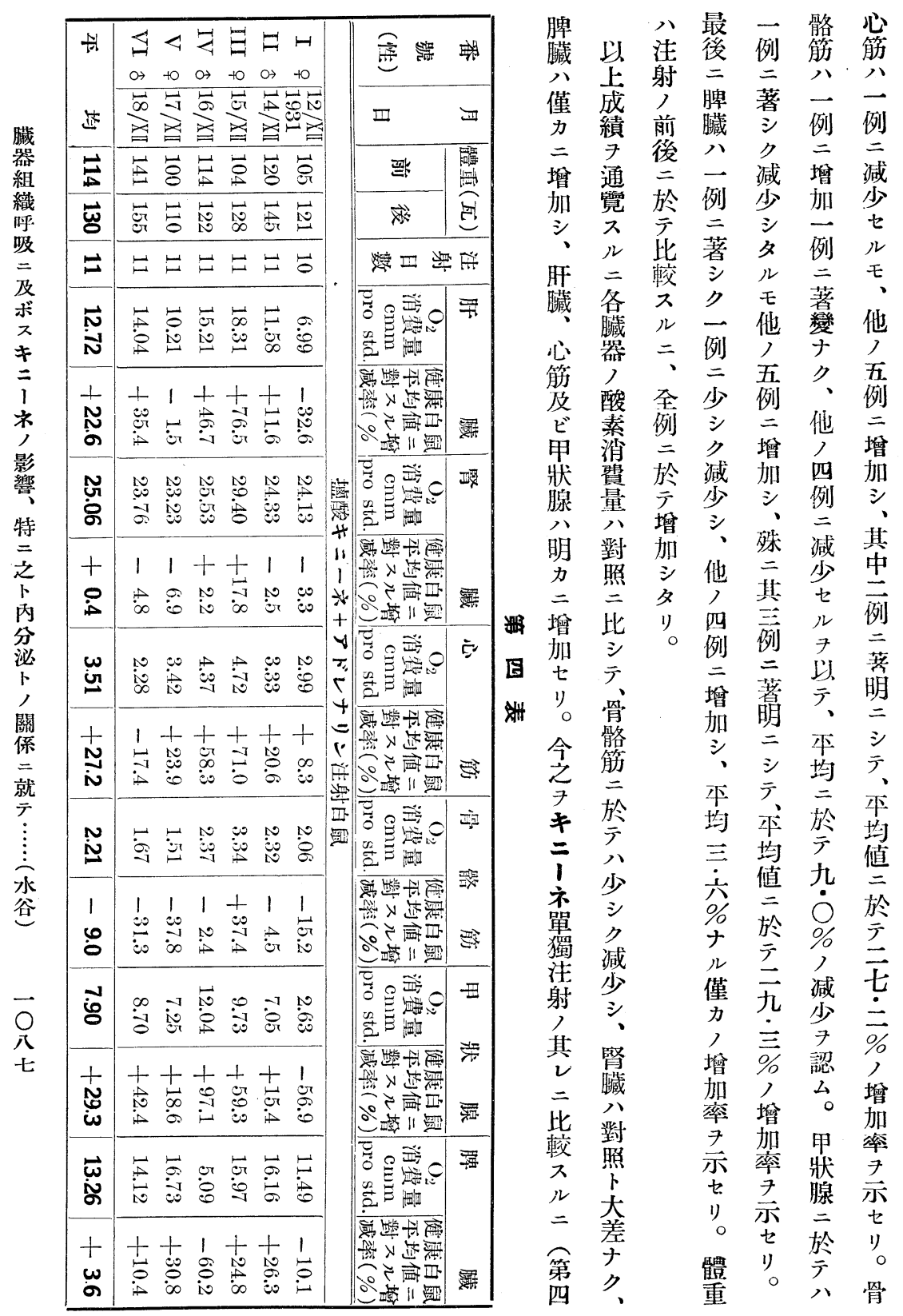




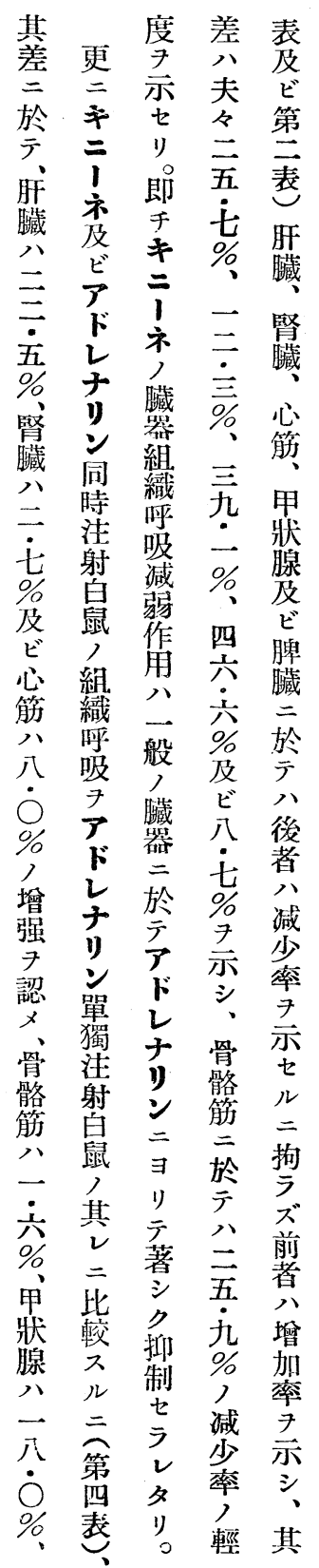

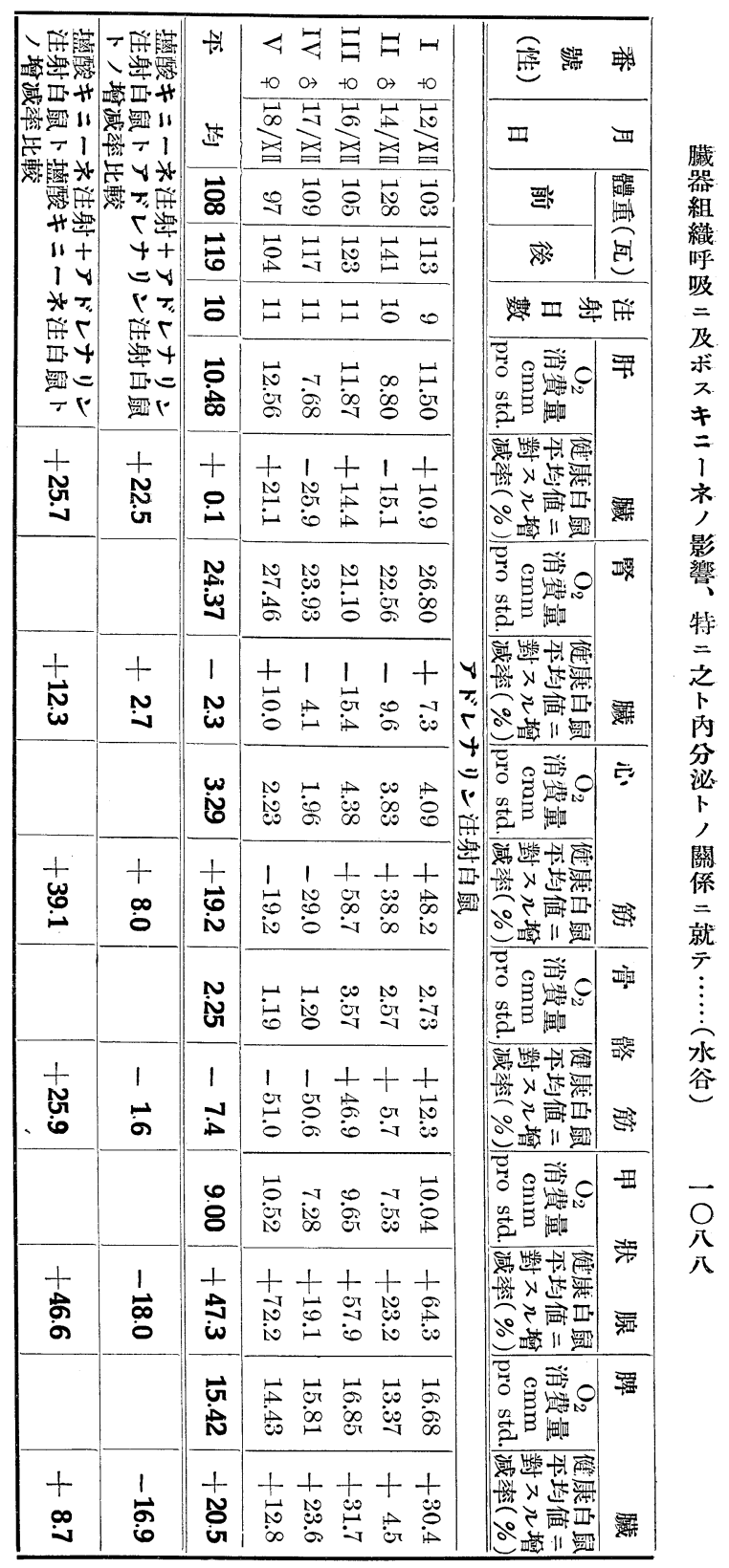




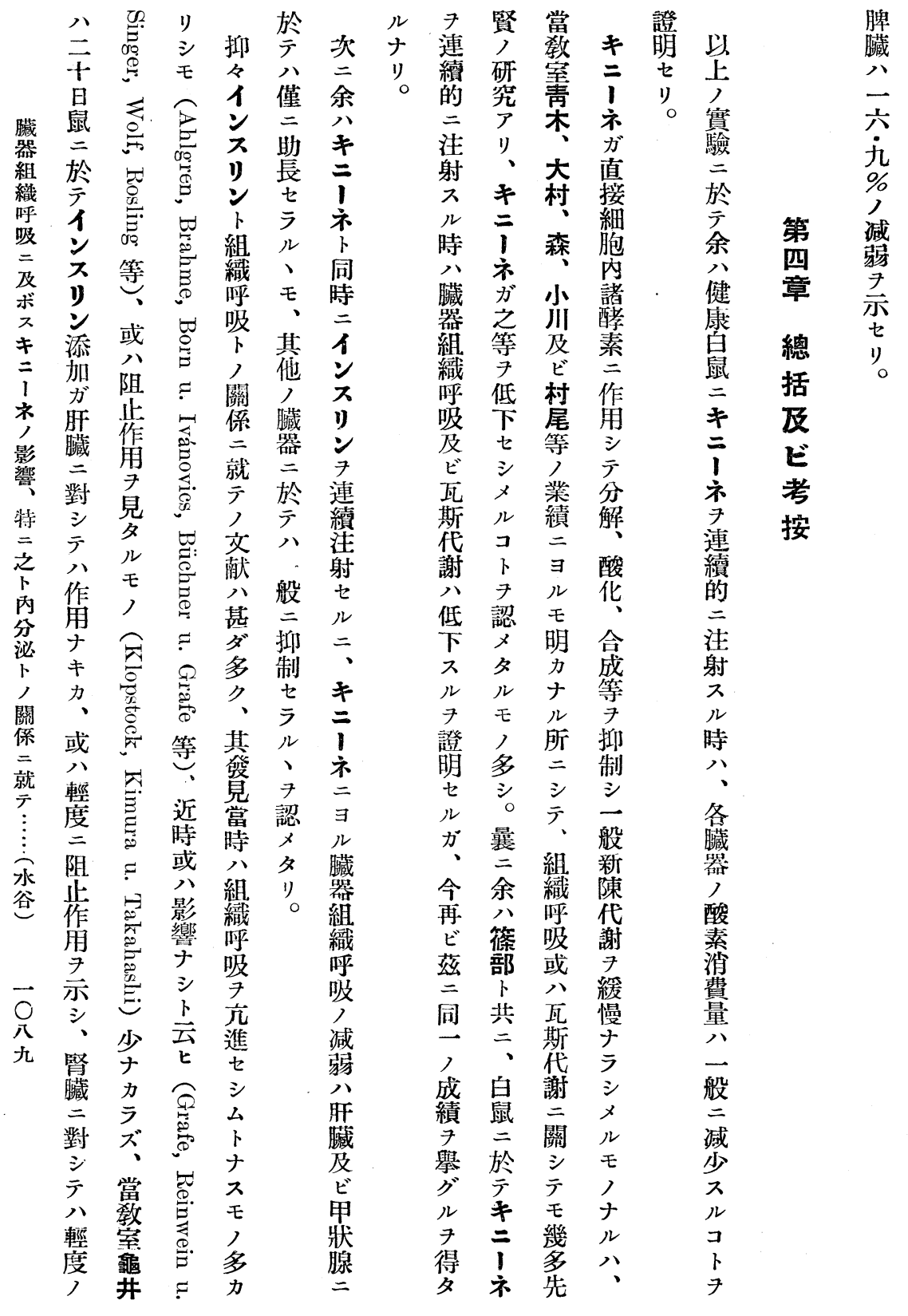




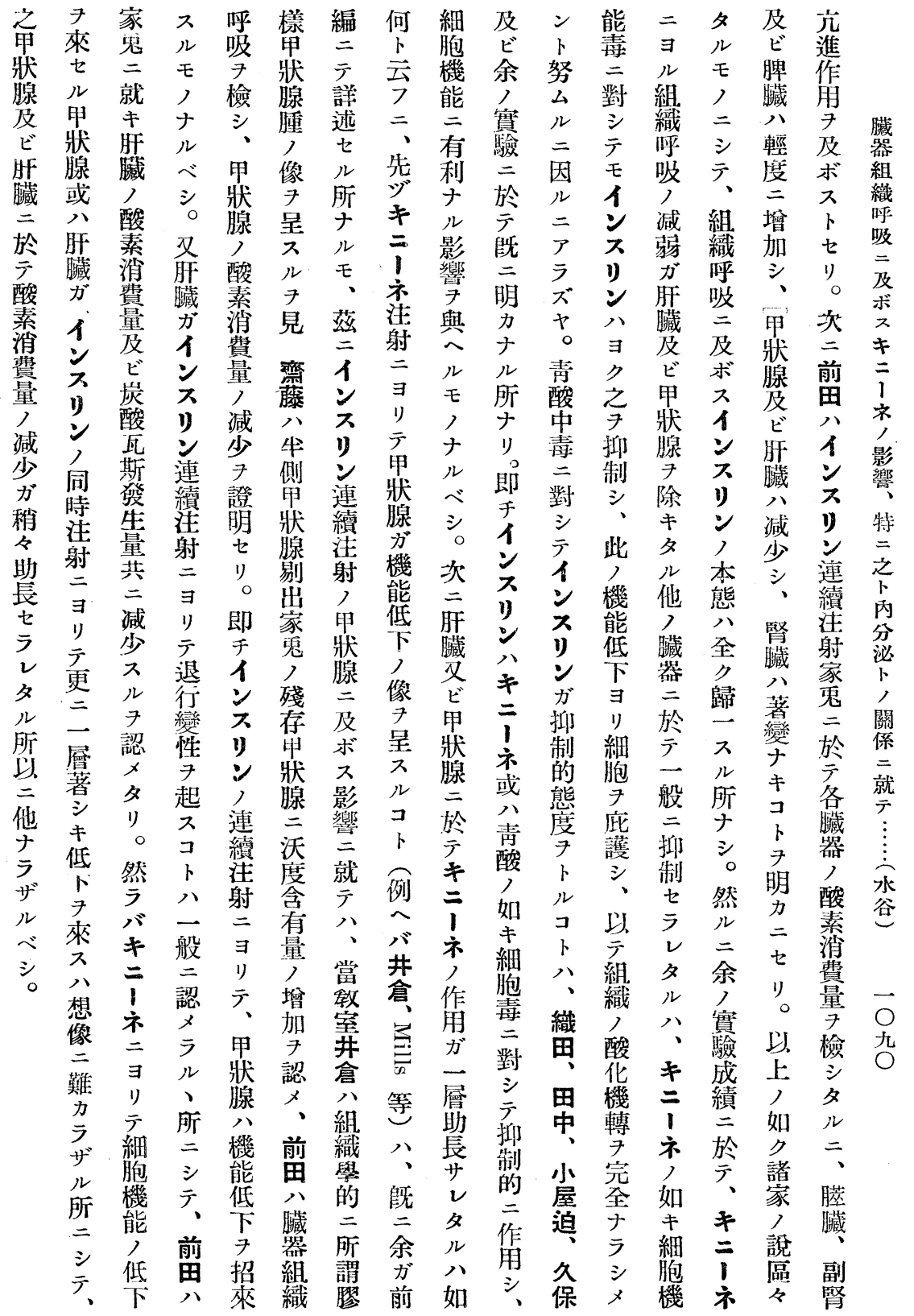




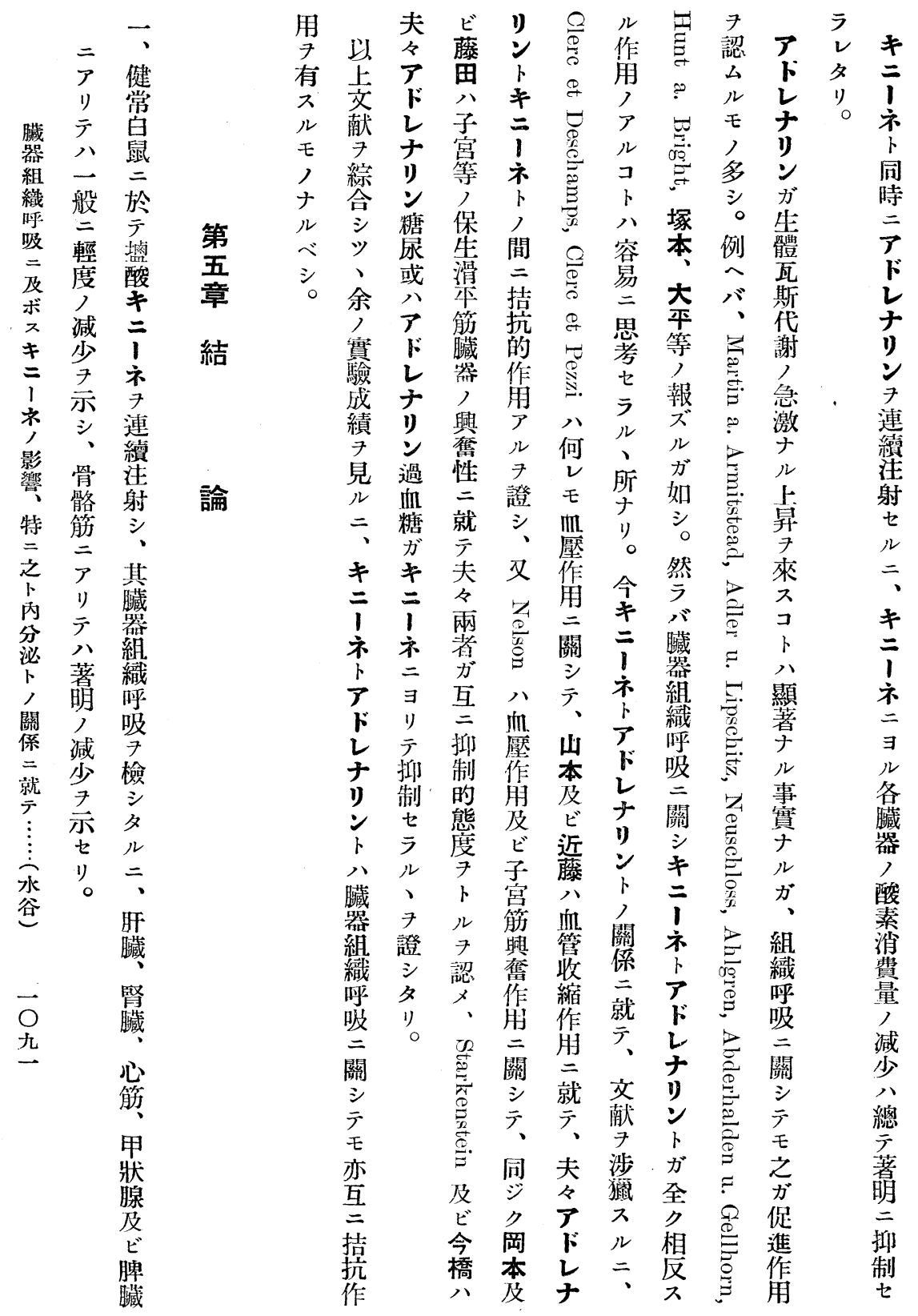




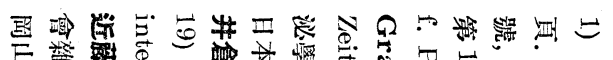

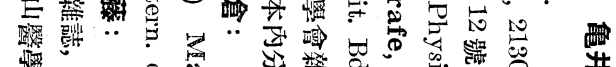

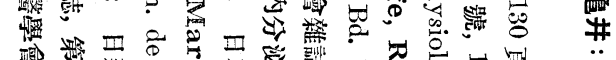

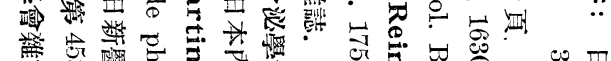

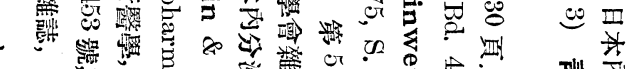

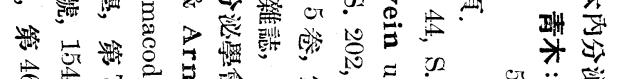

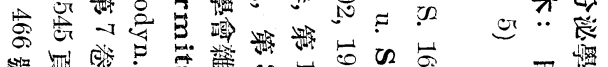

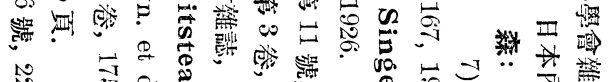

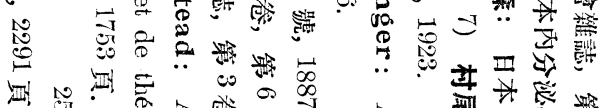

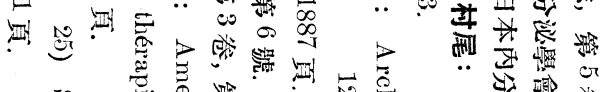

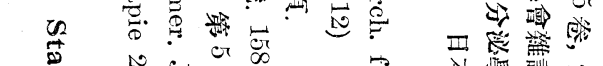

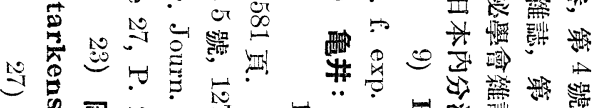

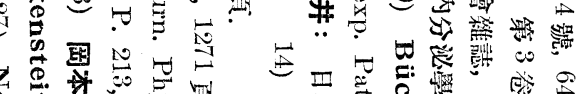

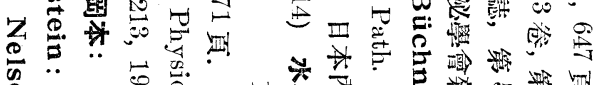

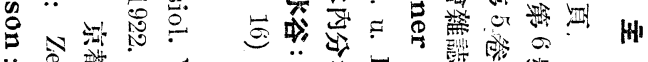

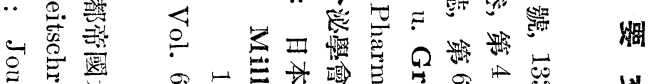

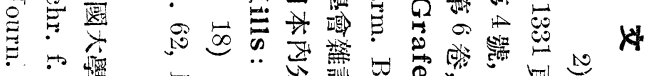

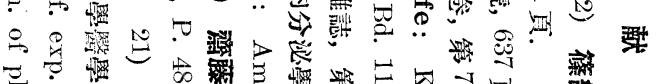

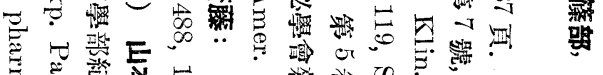

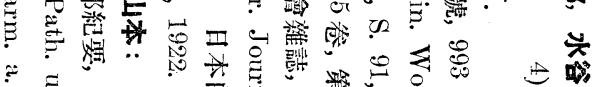

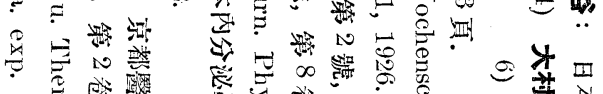
E

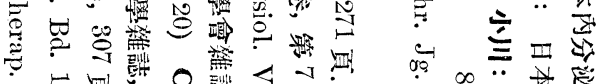

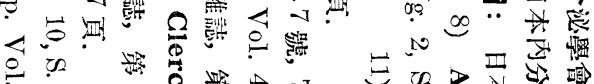

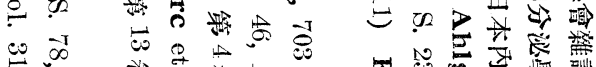

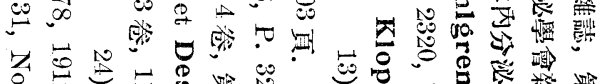

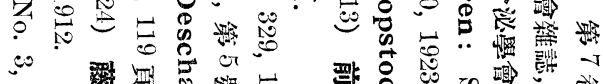

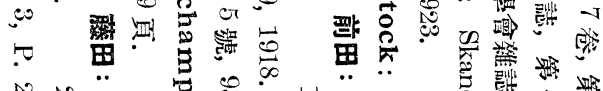

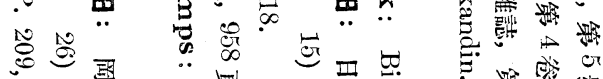

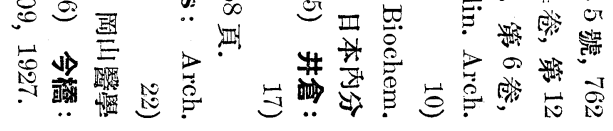

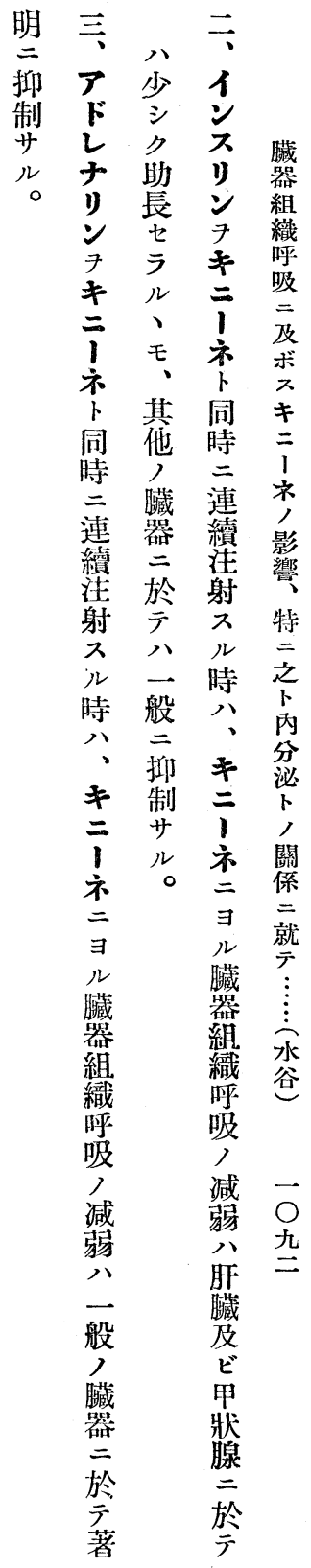


erzeugte Sauerstoffdissoziationskurvenabstieg etwas befördert. Dagegen zeigt bei Fütterung mit kleineren Mengen von Schilddrüsenpulver der durch einmalige Cyankaliinjektion verursachte Abstieg der Sauerstoffdissoziatiationskurve Neigung zur Abnahme.

3) Bei Kaninchen mit exstirpierter Schilddrüse wird der durch Cyankaliinjektion erzeugte Abstieg der Sauerstoffdissoziationskurve deutlich befördert.

(A utoreferat)

\title{
Ueber den Einfluss des Chinins auf die Gewebsatmung und die Beziehung zwischen Ghinin und verschiedenen Hormonen bei derselben.
}

I. Mitteilung. Ueber die Beziehung zwischen Chinin und Insulin oder Adrenalin.

\author{
Von
}

Dr. K. Mizutani.

(Aus der I. med. Klinik der Kaiserl. Universität zu Kyoto in Japan. Direktor: Prof. Dr. K. Tsuji.)

Früher hat der Verfasser über den Einfluss des Chinins auf den Gaswechsel und die Gewebsatmung und die Beziehung zwischen Chinin und Schilddrüse bei derselben mitgeteilt. Die vorliegende Mitteilung berichtet über den Einfluss des Insulins und des Adrenalins auf die Chininwirkung in Bezug auf die Gewebsatmung.

Als Versuchstiere wurden Ratten gebraucht. Die Gewebsatmung wurde mittelst des Barcroftschen Manometers nach Warburg bestimmt.

Die Resultate waren die folgenden:

1) Bei der wiederholten subkutanen Injektion von $2 \%$ iger Chininlösung (täglich pro $100 \mathrm{~g}$ K. G. $0.005 \mathrm{~g}$ Chinin. hydrochlor. 10 Tage lang) findet sich der Sauerstoffverbrauch in der Leber, der Niere, dem Herzmuskel, der Schilddrüse und der Milz im allgemeinen 
leichtgradig und im Skelettmuskel deutlich vermindert.

2) Bei der gleichzeitigen Injektion von Chininlösung und Insulin wird die obenerwähnte durch Chininvergiftung verursachte Abnahme der Gewebsatmung in der Leber und der Schilddrüse etwas verstärkt und in den anderen Organen im allgemeinen gehemmt.

3) Durch gleichzeitige Injektion von Adrenalin und Chininlösung wird die durch Chininvergiftung verursachte Abnahme der Gewebsatmung in allen Organen deutlich gehemmt. (Autoreferat)

\section{Ueber den Einfluss des Chinins auf die Gewebsatmung und die Beziehung zwischen Ghinin und verschiedenen Hormonen bei derselben.}

\section{Mitteilung. Ueber die Beziehung zwischen Ghinin und Geschlechtsdrüsen.}

Von

Dr. K. Mizutani.

(Au↔ der I. med. Klinik der Kaiserl. Universität zu Kyoto in Japan.

Direktor: Prof. Dr. K. Tsuji.)

Der Verfasser untersuchte den Einfluss der Hoden- und Ovariumsubstanz auf die durch Chininvergiftung verursachte Abnahme der Gewebsatmung.

Die Resultate waren die folgenden:

1) Durch die glejchzeitige perorale Verabreichung getrockneter Hodensubstanz mit Chinininjektion wird bei männlichen Ratten die durch Chininvergiftung verursachte Abnahme der Gewebsatmung in der Leber, der Niere, dem Herzmuskel, dem Skelettmuskel und der Milz jm allgemeinen leichtgradig und in der Schilddrüse deutlich gehemmt.

2) Bei der peroralen Verabreichung getrockneter Substanz des 